\title{
ИСТОРИЯ ОБРАЗОВАНИЯ
}

Удк 377.35

\section{Моисеев Андрей Викторович}

соискатель кафедры профессионально-экономического обучения Российского государственного профессионально-педагогического университета, Екатеринбург.

E-mail: moiseev.andrey.2011@mail.ru

\section{Ефанов Андрей Викторович}

кандидат педагогических наук, директор научно-образовательного иентра развития ремесленничества Российского государственного профессионально-педагогического университета, Екатеринбург.

E-mail: efanov.prof@mail.ru

\section{СТАНОВЛЕНИЕ ИНСТИТУЦИОНАЛЬНЫХ ФОРМ РЕМЕСЛЕННОГО ОБУЧЕНИЯ В УРАЛЬСКОМ РЕГИОНЕ B XVII-XVIII BB. ${ }^{1}$}

\begin{abstract}
Аннотация. Цель статьи - показать особенности обучения ремесленным видам деятельности на Урале в XVII-XVIII вв. и выявить возможность использования историко-педагогического наследия ремесленных школ в современной системе профессионального образования.

Mетоды: теоретические - историко-генетический и сравнительный ана-

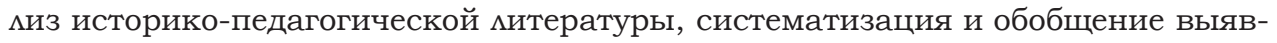
менных тенденций и особенностей развития ремесленного образования; эмпирические - сбор и накопление фактологического материала; анализ источников, их систематизация и классификация.

Результаты. Раскрыта специфика передачи профессионального опыта и мастерства в ремесленных школах уральского региона в XVII-XVIII вв. Рассмотрены ключевые компоненты системы ремесленного обучения, в ходе реамизации которых достигалось развитие способностей обучающихся к предметно-практической деятельности.

Научная новизна. Предложена структура историко-педагогического наследия ремесленного образования, включающая целевой, аксиологический, регулятивный и технологический компоненты.
\end{abstract}

1 Работа выполнена в рамках государственного задания Министерства образования и науки Российской Федерации, проект № 2014/393 «Теоретические и техномогические основы возрождения социального слоя ремесленников-предприниматемей в России". 
Практическая значимость. Выявменные особенности подготовки по ремесленным видам деятельности, сформировавшиеся в прошлом в Уральском регионе, могут быть использованы в современных условиях при проектировании и реализации образовательных программ по ремесленным видам деятельности.

Ключевые слова: ремесленные профессии, ремесленные школы Урала, ремесленное обучение, историко-педагогическое наследие.

\title{
Moiseev Andrey V.
}

Postgraduate, Department of Vocational and Economic Education, Russian State Professional Pedagogical University, Yekaterinburg.

E-mail: moiseev.andrey.2011@mail.ru

\section{Yefanov Andrey V.}

Candidate of Science, Director of Educational Center of Craftsmanship Development, Russian State Vocational Pedagogical University, Yekaterinburg.

E-mail: efanov.prof@mail.ru

\section{FOUNDATION OF INSTITUTIONAL FORMS OF ARTISAN TRAINING IN THE URAL REGION IN THE XVII-XVIII CENTURIES}

\begin{abstract}
The research objective is to demonstrate the specificity of artisan training in the Ural region in the XVII-XVIII centuries, and explore the relating historical and pedagogical heritage and its implementation in the modern vocational training system.

Methods: The applied theoretical methods include the historical and genetic comparative analysis and synthesis of identified trends and specificities of artisan training; empirical methods involve data selection, analysis, systematization and classification.

Results: The research findings reveal the specifics and key components of the artisan training system designed for developing the trainees' abilities and practical skills.

Scientific novelty: The proposed structure of historical pedagogical heritage is specified including the objective, axiological, regulative and technological aspects.

Practical significance: The achieved results concerning the craftsmanship development in the past can be incorporated into the modern vocational training programs.
\end{abstract}

Keywords: artisan occupations, artisan schools of the Ural region, vocational training, historical pedagogical heritage.

На протяжении многих веков обучение ремесленным видам деятельности играло значительную роль в формировании молодого покоцения, его профессиональном и социальном становцении. Ремесленничество как социальный институт вкАючало в себя определенную ду- 
ховно-ценностную основу, национальные традиции, экономические формы и нормативные процедуры функционирования. Все это определямо природу и характер ремесленной деятельности и, соответственно, профессиональную подготовку ее субъекта. И хотя за последнее столетие данный ук^ад жизни был во многом утрачен, но его историко-педагогические составляющие до сих пор представцяют большой интерес и в теоретическом, и в прикладном отношениях.

Осмысление историко-педагогического наследия ремесленных школ становится тем более важным, что в настоящее время растет удельный вес малых ремесленных форм в хозяйственной сфере, что позволяет некоторым специалистам утверждать, что возрождение ремесленного образования дия России - весьма актуальная научная проблема и приоритетная практическая задача [9, с. 63].

Дия Урала, где всегда были сильны традиции ремесленничества, поставленная задача определяется необходимостью исторических изысканий и теоретического осмысления накопленного в прошлом педагогического опыта. На данной территории наиболее четко прослеживаются интегративные процессы, образующие систему генетических предпосылок развития ремесленного образования в виде местных особенностей, технологий, школ мастерства. Однако опыт подготовки ремесленных кадров, сложившийся в Уральском регионе в дореволюционный период, в историко-педагогических исследованиях, по существу, не систематизировался, не находиц теоретического обобщения и тем более обоснования возможности его применения в условиях современной профессиональной школы.

В рамках данной статьи мы рассмотрим особенности становления и развития ремесленного обучения на Урале в XVII-XVIII вв. ${ }^{1}$

На рубеже указанных столетий уральские предприниматели из рода Строгановых одними из первых в России начали осуществлять целенаправленное обучение крепостных мюдей различным ремеслам. В строгановских вотчинах (Сольвычегодске, Усолье, Ильинском) они организовали учебные мастерские, ставшие прообразом профессиональной школы ремесленного труда. В этих "школах" был разработан "Аицевой иконописный подминник", представмявший собой пособие по освоению работы с иконографическими и золотошвейными компо-

1 Под ремесленным обучением здесь и далее нами понимается вид профессиональной подготовки, связанный с созданием материальных продуктов утилитарно-бытового или художественно-эстетического назначения. 
зициями. Начинающие ученики использовали его дмя постижения основ ремесла, а для более подготовценных пособие служило эталоном профессионального мастерства по иконографии, ориентируясь на который, они старались справиться с творческими задачами цветопластики, колорита, орнаментики и продемонстрировать таким образом более продуктивный результат обучения. Такая методика, безусловно, способствовала профессиональному развитию и творческому совершенствованию мичности обучаемого, что было "наиболее ценным эвристическим и могико-аналитическим результатом... образования" [6, с. 6].

Освоение ремесленных видов труда нередко сочеталось с обучением грамоте, но при этом "высокий уровень вцадения ремеслом... не находился в прямой зависимости от уровня книжной образованности мастера" [3, с. 99]. Очевидно, что профессиональный опыт, знания и традиции ремесленной деятельности в подавляющем большинстве случаев передавались от одного поколения к другому в вербальной форме и в виде наглядной демонстрации умений и навыков, а не посредством книг. Так, для строившегося в 1687 г. в Соликамске Богоявленского собора колокола отливали мастера Яков и Иван Аодыгины, не знавшие книжной грамоты, однако в совершенстве владевшие своим делом, следовательно, имевшие познания в области математики, химии, метаммоведения и т. д.

В XVII в. в Соликамске развивалось производство керамических изразцов, применявшихся в строительстве. Изделия изготавливались из красной глины и имели рельефно-полихромную форму. Нередко они расписывались цветными глазурями и эмалями, украшались эмементами декоративной пластики. Обучение данному виду ремесла продолжалось до тех пор, пока ученик не становился самостоятельным работником, и носимо диверсифицированный характер: в процессе освоения основной своей профессии "изразечник" обучаемый овладевал рядом дополнительных специальностей и специализаций - формовщика, резчика, гончара, глазировщика, эмальера и др. Иными словами, мастеровой выполнял не отдельные функции и операции, а осуществля многопцановую, комплексную социально-производственную деятельность. Однако наблюдался и процесс разделения труда: «Становление и развитие профессий всегда было сложным противоречивым процессом. Он одновременно осуществцялся и как интеграция разцичных функций, и как дифференциация" [3, с. 98]. Так, ремесло серебряника в усольских мастерских (горницах) Строгановых XVII в. 
включало комплекс специальных навыков и умений работы с материалом (чеканка, финифть, гравировка, червление, скань), многие из которых впоследствии развились в отдельные самостоятельные профессии.

Немалый вклад в развитие профессионального, в том числе ремесленного, образования на Урале привнес В. Н. Татищев. В 20-е гг. XVIII в. по его инициативе при казенных заводах Екатеринбурга, Уктуса, Алапаевска, Кунгура, Соликамска быми учреждены горнозаводские школы, где наряду с механикой и горным делом осваивались токарное, столярное, оружейное, плотницкое, паяльное, камнерезное, гранильное ремесла. Считалось, что практические знания основных ремесел "каждому ученику полезны и нужны". В Екатеринбургской школе при Канцелярии горных заводов, которая в 1737 г. была преобразована в горнозаводскую, кроме мастеров дмя горной промышменности, чертежников и топографов, готовици камнерезов и столяров-краснодеревщиков. А при основанном под Соликамском в 1743 г. Троицком заводе была учреждена школа, где обучали резчиков по меди, $и$ тейщиков, чеканщиков.

В. Н. Татищеву принадлежит авторство инструкции «Учреждение, коим порядком учители русских школ имеют поступать" (1736 г.), в которой измагались основные требования к организации и содержанию обучения в тот исторический период. Данный документ определял механизмы, обеспечивающие связи общеобразовательной подготовки с профессиональной, обосновывал необходимость соединения теоретического обучения с практической деятельностью в сфере материального производства, устанавцивал режим учебных занятий, регламентировал требования, предъявцяемые к нравственному воспитанию учащихся. Среди прочего в инструкции предписывалось: "Понеже при заводах обучающимся дия собственной пользы, чтоб в чины правления происходить и для пользы заводов, нужно разным необходимым к тем искусствам и ремеслам обучаться, яко: архитектура или учение строений, наука знаменования и живопись к той же архитектуре и прочим наукам в помощь весьма полезна, каменья резать и гранить" [8, с. 172]. С позиций современной педагогики это и подобные наставления можно рассматривать не только как предтечи профильного обучения и построения индивидуальной образовательной траектории ученика, но и как ориентиры достижения им социальной компетентности [4, с. 62].

Значительный интерес представцяет также трактат В. Н. Татищева "Разговор двух приятелей о пользе науки и училищах" (1733 г.), 
в котором он рекомендовал: “Чтобы ученики охотнее и скорее обучамись, при этом меньше надзирания и принуждения требовали, для чего использовать похвалу". Таким образом, дмя побуждений к учению использовались преимущественно положительные стимулы, а также поощрялись склонности к постоянным проявлениям трудолюбия и старательности.

Одним из первых В. Н. Татищев применил методику взаимного обучения, суть которой заключалась в том, что старшим по возрасту и уровню подготовки ученикам вменялось в обязанность обучать младших. Позднее данный способ передачи знаний и умений получил известность как "методика Бемл- $А$ анастера", разработанная в конце XVIII в. британскими учеными и взятая на вооружение отечественной школой на более позднем этапе [6, с. 9].

C середины XVIII в. на Урале создаются учебные заведения и при частных заводах. Так, в 1758 г. Н. А. Демидов учреждает в Нижнем Тагиме горнозаводское училище, где теоретические занятия дополнялась практическим обучением. Необходимость последнего обосновывалась наказом В. Н. Татищева, в котором содержался следующий пункт: "Когда которые возрастные обучатся геометрии, оных немедленно определять в работы, к каким делам кто охоту возымеет...". И еще: "Веметь ученикам...не токмо присматриваться, но и руками по возможности применяться в искусстве ремесла, в чем оное состоит - внятно уведомиться и рассуждать: из чего мучше или хуже может быть, которые мастера ремесел должны им открывать" [7, с. 316]. При обучении крепостные тагильских заводов должны были не только приобретать профессиональные знания и умения, но и готовиться к тому, чтобы впоследствии самим, выражаясь современным языком, заниматься педагогической деятельностью, т. е. обеспечивать себе смену [10, с. 52].

В хозяйстве заводчиков Демидовых к наставничеству активно привлекались и крепостные ремесленники, которых "обязывали обучать и передавать... приемы и навыки своей профессии, приобретенные ... самостоятельно в процессе непрерывной практической деятельности" $[10$, с. 52]. Так, согласно предписанию Н. А. Демидова за 1778 г. для освоения слесарного и макового дела в мастерскую крепостного тагильских заводов А. С. Худоярова с сыновьями были определены ученики, обучение которых продолжалось в течение нескольких мет и основывалось на $и$ нном показе наставниками приемов и секретов работы. Диительный срок обучения оправдывался сложностью перени- 
маемого ремесла: ученики домжны были овладеть умениями, как "работать красками, серебром и золотом и метамиическими песками на меди, железе, бумаге и дереве, ... цыровить ${ }^{1}$ золотом и черние по разным землям на столах, комодах и других вещах... и все таковые вещи разными маками покрывать, составлять краски и маки самые прочные и хорошего цвета" [1].

Помимо обучения при государственных и частных заводах в Зауралье в XVIII в. существовали и развивались общественные каналы трансляции профессионального опыта и мастерства: создавались товарищества и цеховые корпорации, объединявшие ремесленников одной профессии. Внутри них осуществлялась подготовка молодежи к определенному виду трудовой деятельности, которой нередко сопутствовало обучение элементарному чтению, счету и письму. Известно и то, что при Далматовском Успенском, Верхотурском Николаевском и других крупных монастырях также велось групповое обучение размичным ремеслам в сочетании с общим образованием.

Таким образом, освоение ремесел в рассматриваемый период происходимо, как правицо, непосредственно в процессе социальнопроизводственной деятельности. В общем виде содержание ремесленного обучения вкцючало в себя следующие виды знаний: о предмете и его производстве; материале, из которого производится предмет; происхождении этих предмета и материала; способах производства предмета; применении предмета [3, с. 100]. Ученики обязаны были овладеть в полной мере практическими умениями и навыками работы с конкретным материалом, использующимся в осваиваемом ремесменном деме.

Само собой, что при таком обучении производственные методы и приемы превалировали над педагогическими. Это придавало подготовке ремесленника особый практический "рецептурный" характер. Когда между образовательной и производственной деятемьностью еще не существовало "посредника" в виде педагогической науки, будущие мастера учимись одновременно и тому "как демать", и тому "как обучать других". Приемы и методы наглядного обучения (демай как я) производственным способам работы и секретам ремесла транслиро-

\footnotetext{
1 Цыровить (от нем. zieren - украшать) - способ художественного оформления, представляющий собой процарапывание затупленной иглой красочного слоя до поверхности мистового золочения в целях воспроизведения тонкими Аиниями орнамента по золоту.
} 
вались последующим поколениям учеников и становились традиционными педагогическими приемами и методами.

Несмотря на то, что обучение видам ремесленного труда носимо диверсифицированный характер, выбор специализации определялся тем, к какому мастеру (Аичнику ${ }^{1}$, доличнику ${ }^{2}$, уставщику ${ }^{3}$ ) попадал ученик. И не специализация, а уровень мастерства определял профессиональный статус ремесленника. Степень достигнутых в ходе обучения результатов, в свою очередь, зависела от мичностных качеств наставника, в мастерской которого осваивалось то или иное ремесло. Следовательно, в содержании подготовки ремесленника существенную роль играл "взаимообусловливающий характер отношений между мичностными и профессиональными составцяющими" [11, с. 288].

В практическую учебную деятельность быц также включен процесс воспитания. Немалая роль отводимась формированию нравственного отношения будущего ремесленника к выполнению своих профессиональных обязанностей (производственно-трудовых, идеально-проективных), что способствовало, на языке сегодняшней педагогической науки, профессиональной социализации и самоактуализации подмастерий. Данное обстоятельство в значительной степени объясняется спецификой ремесленной деятельности, в которой индивидуальный, автономный труд требует тем не менее наличия целого ряда коммуникативных и организационных качеств.

Подводя итог, деятельность своеобразных "обучающих центров", существовавших на Ураме в XVII - начале XVIII вв., можно охарактеризовать как неразрывное единство производственного и образовательного процессов. Обучение было достаточно синкретичным: ученики обучались, производя продукцию, и производили ее, обучаясь. Постижение учебного материала опиралось на предшествующий опыт, факты, традиции. Категории "ремесленная традиция" и "мокальная культурная традиция" (канон) охватывали технологии (способы и приемы обработки материала), ассортимент изделий, формы организации производства и организационно-педагогические формы подготовки мастеров-ремесленников. Апемлируя к учению Ф. Энгельса о трех видах производства, Н. К. Чапаев заключает, что "на данном уровне... произ-

\footnotetext{
1 Иконописец, специализировавшийся на изображении миц, рук, обнаженного тела.

2 Мастер-иконописец, писавший ризы и облачения.

3 Мастер, выполнявший надписи на иконах.
} 
водство вещей, производство и воспроизводство Аюдей как социальных субъектов составляли одно синкретическое цемое» [11, с. 287]. Такое обучение создавало культурно-продуктивную преемственность поколений и идентифицировало национально-культурную целостность социума, крепимо, по выражению С. З. Гончарова, традиционное общество "снизу" [2, с. 16].

Анализ форм ремесленного образования на Урале в XVII-XVIII вв. позволиц выделить в нем четыре составцяющих историко-педагогического наследия: цемевой, аксиологический, регулятивный и технологический компоненты (рисунок).

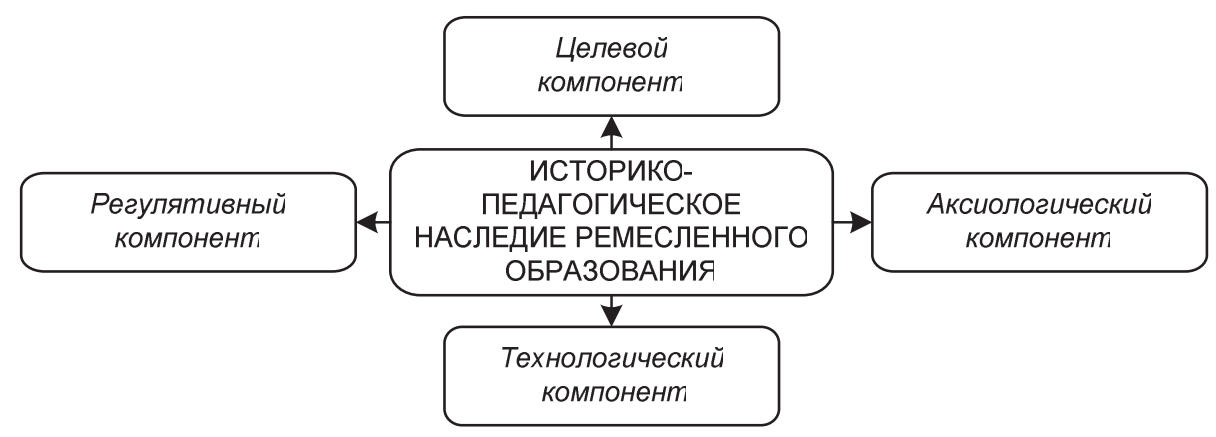

Структура и содержание историко-педагогического наследия ремесленного образования

Целевой компонент историко-педагогического наследия ремесменного образования базируется на идее организации такого типа подготовки, в которой обучение и ремесленное производство представляет собой единое синкретичное целое, обеспечивая, с одной стороны, формирование "целостного человека", с другой стороны, воспроизводство человека "продуктивной ориентации", способного осуществцять профессиональную деятельность во всей "экзистенциальной полноте» бытия.

Аксиологический компонент включает в себя ряд признаков, раскрывающих ценностные аспекты ремесленного образования. Во-первых, оно выполняет "человекотворящую функцию", так как в сфере ремесленной подготовки происходит вхождение человека в целостную учебно-профессиональную деятельность, которая по содержанию и условиям психологически и практически приближена к деятельности реальной. Во-вторых, система ремесленного образования обеспечивает естественную преемственность поколений через на- 
копление, сохранение и передачу социально-культурного опыта и профессионального мастерства в сфере материального производства. В-третьих, сфера ремесленного образования, несмотря на наличие в ремесменной деятельности элементов редукции, наделена мощным креативно-антропологическим содержанием, необходимым дия творческого развития человека.

Регулятивный компонент содержит нормативно оформкенные процедуры функционирования ремесленной подготовки (законодательные акты, постановления органов государственной вцасти и местного самоуправления, образовательные программы, квалификационные требование и др.) и нормативно неоформленные процедуры (традиции, устои, обычаи, образцы поведения и пр.).

Технологический компонент историко-педагогического насмедия ремесленного образования включает в себя ряд дидактических и эвристических оснований, определяющих подбор методического инструментария и средств ремесленного обучения. К таковым можно отнести:

- последовательное овладение навыками работы с инструментами и материалами;

- непосредственную преемственную связь с опорой на предшествующий положительный опыт и традиции изготовления изделий;

- опытно-пробное постижение новых материалов и технологических приемов исполнительского мастерства;

- многократное копирование образца изделия со стремлением к его полному воспроизведению (идентичности);

- имитацию, точное повторение образца и стремление к сохранению в новых изделиях основных признаков оригинала, но без обязательной идентичности;

- внешний контроль за результативностью обучения посредством постоянного сопоставцения образца с изготавциваемым изделием;

- стимулирование освоения основ мастерства, поддержку склонности к постоянному проявлению трудолюбия и старательности [5, с. 93].

Исследование закономерностей, позволяющих прогнозировать, проектировать и организовывать образовательный процесс, относится к числу основных задач современной профессиональной школы, решение которых во многом определяет ее дальнейшее развитие. Одним из приоритетов в изучении фундаментальных основ профессионального образования были и остаются описание и анализ историко-педа- 
гогического наследия: выработанных временем принципов, содержания, методов, средств, форм, целей обучения и воспитания - и поиск на данном материале наиболее перспективных, приемлемых для реамизации в современных условиях путей совершенствования подготовки будущих специалистов-профессионалов, в том числе ремесленников. Историко-педагогические факты требуют бережного сохранения и осмысления. Мы не сомневаемся, что, по мере совершенствования существующих и утверждения принципиально новых регулятивных основ ремесленной деятельности и подготовки кадров для активизирующегося ремесленного сектора экономики, цучший опыт отечественной ремесленной школы будет востребован в новых образовательных реалиях.

Рекомендовано к печати академиком РАО, д-ром пед. наук, проф. Г. М. Романиевъми

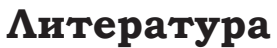

1. ГАСО. Ф. 643. Оп. 1. Д. 302. А. 1, 2.

2. Гончаров С. З. Креативность ремесленной деятельности // III Худояровские чтения. Н. Тагим: Медиа-Принт, 2008. С. 14-16.

3. Горнозаводские школы как феномен русской педагогической культуры / Н. К. Чапаев [и др.]. Екатеринбург: РГППУ, 2008. 196 с.

4. Грибенюк Г. Г. Педагогические условия формирования социальной компетентности обучающихся горнозаводских школ Урала // Педагогическое образование в России. 2008. № 1 (2). С. 60-62.

5. Днепров С. А., Максяшин А. С. Генезис художественного образования в области изобразительного искусства Урала (методология, история и перспективы) // Образование и наука. Изв. УрО РАО. 2007. № 6 (48). С. 89-100.

6. Днепров С. А., Максяшин А. С. Художественное образование в области изобразительного искусства Урала как зеркало модернизаций XVIII-XX вв. / / Педагогическое образование в России. 2010. № 2 (9). С. 6-15.

7. Заводской устав В. Н. Татищева (1734-1736 гг.) // Горный журнал. С.-Петербург, 1831. Ч. 3. Кн. 9. С. 316-319.

8. Инструкция В. Н. Татищева о порядке преподавания в школах при уральских казенных заводах // Исторический архив. Москва, 1950. Т. V. C. $166-178$

9. Романцев Г. М., Ефанов А. В. Ремесленники XXI века: впереди эпоха Ренессанса // Аккредитация в образовании. 2012. № 12 (60). С. 62-64.

10. Симонова О. Н. Крепостные художники Демидовых. Учимище живописи. Худояровы. XVIII-XIX вв. Из истории подготовки специалистов художественных и художественно-ремесленных профессий Демидовыми. Екатеринбург: Баско, 2007. 416 с.

11. Чапаев Н. К. Реинтегративная миссия ремесленного образования // Становление и развитие ремесленничества и профессионального ремесленного образования в России. Екатеринбург: РГППУ, 2011. С. 285-291. 


\section{References}

1. State Archive of Sverdlovskaya Oblast. Resource 643; Inventory no. 1, File 302, List 1 (In Russian)

2. Goncharov S. Z. Kreativnost' remeslennoj dejatel'nosti [Creativity of Craftsmanship]. III Khudoyarouskie Readings. N. Tagil.: Media-Print. 2008. V. 3. P. 14-16. (In Russian)

3. Chapaev N. K. i dr. Gornozavodskie shkoly kak fenomen russkoj pedagogicheskoj kul'tury. [Mining Schools as Russian Pedagogical Culture Phenomenon]. Yekaterinburg: RSVPU. 2008. 196 p. (In Russian)

4. Gribenjuk G. G. Pedagogicheskie uslovija formirovanija social'noj kompetentnosti obuchajushhihsja gornozavodskih shkol Urala. [Pedagogical Conditions for the Social Competence development of Ural Mining Schools Students]. Pedagogicheskoe obrazovanie v Rossii [Pedagogical Education in Russia]. 2008. Vol. 2. № 1. P. 60-62. (In Russian)

5. Dneprov S. A., Maksjashin A. S. Genezis hudozhestvennogo obrazovanija v oblasti izobrazitel'nogo iskusstva Urala (metodologija, istorija i perspektivy) [The Genesis of artistic Education in Ural Fine Arts Field (methodology, history and prospects)]. Obrazovanie i nauka. Izv. UrO RAO. [Education and Science. News of Ural Branch of Russian Academy of Education]. 2007. Vol. 48. № 6. P. 89-100. (In Russian)

6. Dneprov S. A., Maksjashin A. S. Hudozhestvennoe obrazovanie v oblasti izobrazitel'nogo iskusstva Urala kak zerkalo modernizacij XVIII-XX vekov. [Artistic Education in the Ural Fine Arts Field as the mirror of Modernization in XVIIIXX centuries]. Pedagogicheskoe obrazovanie $v$ Rossii [Pedagogical Education in Russia]. 2010. Vol. 9. № 2. P. 6-15. (In Russian)

7. Zavodskoj ustav V. N. Tatishheva (1734-1736 gg.). [Works Regulations by Tatischev (1734-1736)]. Gornyj zhurnal. [Mining Magazine]. St. Petersburg, 1831. Part 3. Vol. 9. P. 316-319. (In Russian)

8. Instrukcija V. N. Tatishheva o porjadke prepodavanija $\mathrm{v}$ shkolah pri ural'skih kazennyh zavodah Tatischev's [Instruction about School Tutoring at Ural State Works]. Ist. arhiv [Historical Archive]. 1950. Vol. 5. P. 166-178. (In Russian)

9. Romancev G. M., Efanov A. V. Remeslenniki XXI veka: vperedi jepoha Renessansa. [Craftsmen of the XXI century: Renaissance Epoch ahead]. Akkreditacija $v$ obrazovanii [Accreditation in Education]. 2012. Vol. 60. № 12. P. 62-64. (In Russian)

10. Silonova O. N. Krepostnye hudozhniki Demidovyh. Uchilishhe zhivopisi. Hudojarovy. XVIII-XIX veka. Iz istorii podgotovki specialistov hudozhestvennyh i hudozhestvenno-remeslennyh professij Demidovymi. [Serf Artists of Demidovs. Fine Art College. Khudoyarovs. XVIII-XIX century. From the history of artistic and artistic crafts training by Demidovs]. Yekaterinburg: Basco. 2007. 416 p. (In Russian)

11. Chapaev N. K. Reintegrativnaja missija remeslennogo obrazovanija. [Reintegrating Mission of Trade Education]. Ekaterinburg: RSVPU. 2011. P. 285-291. (In Russian) 